\title{
Prevalencia de anticuerpos antifosfolípidos en pacientes con conectivopatías
}

\author{
Prevalence of antiphospholipid antibodies in patients with connective tissue diseases
}

\author{
Óscar Emilio Ruiz-Franco ${ }^{1,2}$, Marco Enrique Guerrero-Vásquez², \\ Carlos Montenegro-Verástegui ${ }^{2}$, David Alberto Díaz-Robles ${ }^{2}$, \\ Carlos Alberto Delgado-Silva ${ }^{1,2}$, Manuela Marangoni de Ruiz ${ }^{2}$ \\ ${ }^{1}$ Instituto de Investigaciones Clínicas, Facultad de Medicina, Universidad Nacional Mayor de San Marcos. \\ ${ }^{2}$ Servicio Hematología Clínica, Hospital Nacional Dos de Mayo, Lima, Perú.
}

\begin{abstract}
Resumen
Objetivos: Determinar la prevalencia de anticuerpos antifosfolípidos en pacientes con conectivopatías. Diseño: Estudio descriptivo transversal. Institución: Hospital Dos de Mayo e Instituto de Investigaciones Clínicas de la UNMSM, Lima, Perú. Participantes: Pacientes con diagnóstico de colagenopatía y sujetos sanos. Intervenciones: En 100 pacientes con diagnóstico de colagenopatía y 50 sujetos sanos, todos provenientes de Lima Metropolitana y atendidos entre enero y noviembre de 2008, se determinó fibrinógeno, tiempo de protrombina, tiempo parcial de tromboplastina activada, anticuerpos anticardiolipina y anticoagulante lúpico. Principales medidas de resultados: Presencia de anticuerpos anticardiolipina y anticoagulante lúpico. Resultados: Los pacientes con conectivopatías presentaron anticuerpos antifosfolípidos en 17\%, anticoagulante lúpico en 13\% y anticardiolipina lgG 4\%. Al dividir el grupo por conectivopatías, en los 70 pacientes con lupus eritematoso sistémico 10 resultaron positivos para anticoagulante lúpico y 3 tuvieron anticardiolipina lgG; de los 30 pacientes con artritis reumatoide, 3 tuvieron anticoagulante lúpico positivo y 1 presentó anticardiolipina IgG. En el grupo de 50 personas sanas, solo se encontró un caso positivo para anticoagulante lúpico. Conclusiones: La prevalencia de anticuerpos antifosfolípidos en pacientes con conectivopatías fue $17 \%$. La conectivopatia estudiada más frecuente fue el lupus eritematoso sistémico. El anticuerpo antifosfolípido más frecuente fue el anticoagulante lúpico.
\end{abstract}

Palabras clave: Síndrome antifosfolipídico, conectivopatias, trombosis.

Abstract

Objectives: To determine the prevalence of antiphospholipid antibodies in patients with connective tissue diseases. Design: Descriptive transversal study. Setting: Dos de Mayo Hospital and Institute of Clinical Research, San Marcos University, Lima, Peru. Participants: Patients with diagnosis of collagen disease and healthy subjects. Interventions: In 100 patients with collagen disease and 50 healthy subjects, all from Metropolitan Lima and attended between January and November 2008, fibrinogen, prothrombin time, partial activated thromboplastin time, anticardiolipin antibody and lupus anticoagulant were determined. Main outcome measures: Presence of anticardiolipin antibodies and lupus anticoagulant. Results: Patients with collagen diseases presented antiphospholipid antibodies in $17 \%$, lupus anticoagulant in 13\%, and IgG anticardiolipin in 4\%. Individualizing connective tissue diseases, in 70 patients with systemic erythematous lupus 10 were positive for lupus anticoagulant and 3 had $\operatorname{lgG}$ anticardiolipin; of 30 patients with rheumatoid arthritis three were positive to lupus anticoagulant and one presented IgG anticardiolipin. In the group of 50 healthy individuals, only one was positive for lupus anticoagulant. Conclusions: The prevalence of antiphospholipid antibodies in patients with connective tissue was $17 \%$. The most frequent connective tissue disease studied was lupus erythematosus and the most frequent antiphospholipid antibody found was lupus anticoagulant.

Key words: Phospholipid antibodies, connective tissue disease, thrombosis.

An Fac med. 2011;72(3):187-90

\section{INTRODUCCIÓN}

A medida que el ser humano tiene más edad, está propenso a desarrollar enfermedades autoinmunes, conectivopatías y neoplasias. Dentro de las complicaciones de estas enfermedades se encuentran las trombosis venosas y arteriales ${ }^{(1)}$. Así, por ejemplo, el sín- drome antifosfolipídico tiene como característica importante la presentación de trombosis adquirida, sobretodo de tipo venoso, debido a la presencia de anticuerpos dirigidos contra los factores de coagulación (2).

Las enfermedades del tejido conectivo (lupus eritematoso sistémico, artritis reumatoidea, esclerosis sistémica, entre otras) pueden inducir la formación de autoanticuerpos antifosfolípídos y por lo tanto producir trombosis en los pacientes que las presentan ${ }^{(1,3)}$. Los anticuerpos antifosfolípidos son de dos tipos: anticoagulante lúpico y anticuerpo anticardiolipina. Así, a nivel internacional se conoce que los pacientes con 
lupus eritematoso sistémico, así como otras conectivopatías, pueden presentar anticoagulante lúpico y anticardiolipina entre 10 y $25 \%{ }^{(4)}$.

Varios estudios en pacientes con conectivopatías, como lupus eritematoso sistémico, han sugerido que el anticoagulante lúpico es probablemente más frecuentemente asociado a esta entidad clínica que los anticuerpos anticardiolipina ${ }^{(5-7)}$.

El síndrome antifosfolípido causa trombosis venosa y arterial de pequeños y grandes vasos, pérdida del embarazo, parto prematuro en pacientes con insuficiencia placentaria o preeclampsia grave. Otras manifestaciones clínicas son enfermedad cardíaca, renal, microangiopatía trombótica, trombocitopenia, anemia hemolítica y deterioro cognitivo. Los anticuerpos antifosfolípidos promocionan la activación de las células endoteliales, monocitos y plaquetas, y la sobreproducción de factor tisular y tromboxano A2. La activación del complemento podría tener un papel central patogénico ${ }^{(8)}$.

La población peruana tiene como característica epidemiológica la de mantener aún una incidencia alta de enfermedades infecciosas, y un aumento progresivo de enfermedades degenerativas, del colágeno y neoplásicas ${ }^{\left({ }^{9}\right.}$.

El objetivo del presente estudio fue evidenciar la prevalencia de anticuerpos antifosfolipidos en pacientes con conectivopatías.

\section{MÉTODOS}

Se realizó un estudio descriptivo transversal, llevado a cabo en el Instituto de Investigaciones Clínicas de la Universidad Nacional Mayor de San Marcos (UNMSM) y en el Hospital Nacional Dos de Mayo, durante el período de enero a noviembre de 2008. Participaron en el estudio 100 pacientes con diagnóstico de colagenopatía y 50 sujetos sanos, todos provenientes de

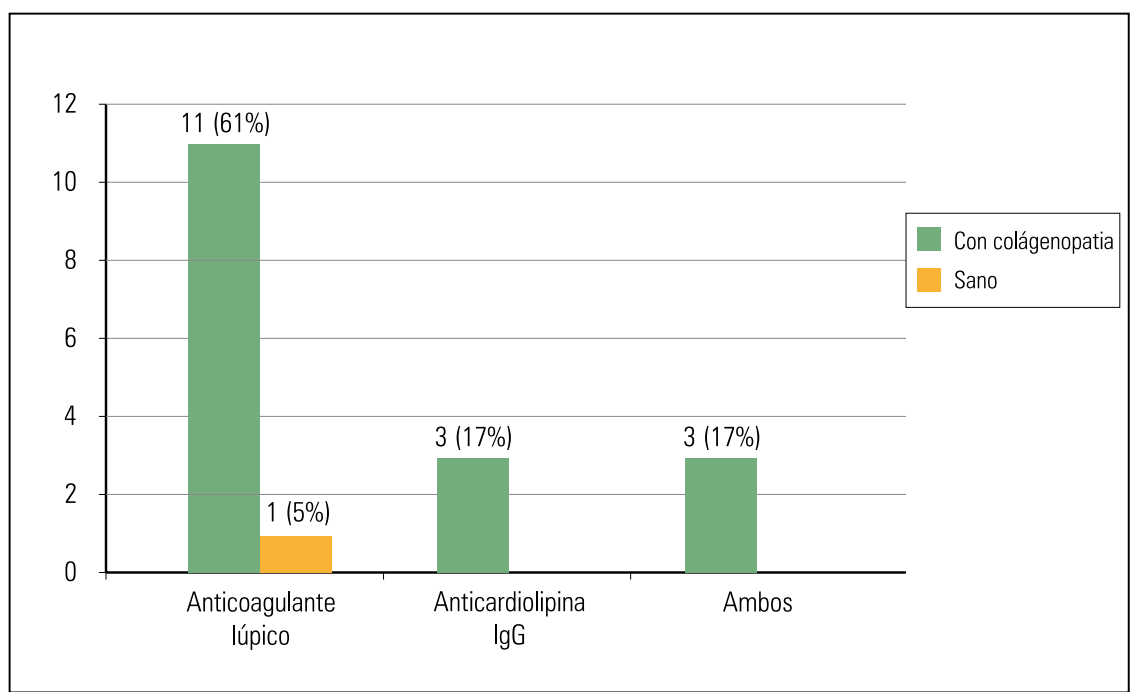

Figura 1. Número de pacientes con anticuerpos antifosfolipídicos, en los dos grupos de estudio.

Lima Metropolitana. Se procedió a la determinación laboratorial del perfil de coagulación básico -fibrinógeno, tiempo de protrombina, tiempo parcial de tromboplastina activada-, así como la detección de anticuerpos anticardiolipina y anticoagulante lúpico.

Se incluyó pacientes mayores de 18 años y sin antecedente de enfermedad hepática concomitante, excluyéndose a los pacientes con terapia anticoagulante y a las gestantes. Se consideró como valores normales:

- Fibrinógeno: 150 a 400 mg\%

- Tiempo de protrombina: $12 `( \pm 2 `)$

- Tiempo parcial de tromboplastina: $35^{`}\left( \pm 10^{`}\right)$

- Anticuerpos antifosfolipídicos:

- Anticoagulante lúpico: $37^{\circ}( \pm$ 10')

- Anticardiolipina IgG: $\leq 20 \mathrm{GPL}$ (IgG anticardiolipin units) unidades.

Todas las personas incluidas en el estudio firmaron un acta de consentimiento informado. Los resultados fueron estratificados de manera porcentual.

\section{RESULTADOS}

Participaron del estudio 150 sujetos -100 pacientes con conectivopatías y 50 personas sanas-; de ellas, 120 fueron mujeres y 30 varones. La edad promedio fue 24 años, con un rango de 18 a 52 años. Del total de pacientes con conectivopatías, 70 presentaron lupus eritematoso sistémico (LES) y 30 artritis reumatoide (AR). De ellos, 17\% de pacientes con conectivopatías presentó anticuerpos antifosfolipídicos, mientras del grupo control solo uno tuvo anticuerpos antifosfolipídicos (2\%) (figura 1).

$\mathrm{Al}$ estudiar la distribución de anticuerpos antifosfolipídicos dentro de estas patologías, se evidenció que de los pacientes con LES y AR, 13 y 4 personas dieron positivo para anticuerpos antifosfolipídicos, respectivamente. Al estudiar por tipo de anticuerpo, $10 \mathrm{pa}$ cientes del total expresaron positividad para anticoagulante lúpico (10\%), 4 para anticardiolipina (4\%) y 3 pacientes (3\%) para ambos anticuerpos (tabla 1).

Dentro del grupo con LES, 7 pacientes fueron positivos para anticoagulante lúpico, 3 para anticardiolipina $\operatorname{IgG}$ y 3 para ambos. En los pacientes con AR, 3 resultaron positivos para anticoagulante lúpico y 1 para anticardiolipina IgG. 
Tabla 1. Porcentaje de pacientes que presentaron anticuerpos antifosfolipídicos, según enfermedad del tejido conectivo.

\begin{tabular}{|c|c|c|}
\hline \multicolumn{1}{|c}{$\begin{array}{c}\text { Anticuerpos } \\
\text { antifosfolipídicos }\end{array}$} & $\begin{array}{c}\text { Lupus eritematoso } \\
\text { sistémico (13) }\end{array}$ & $\begin{array}{c}\text { Artritis } \\
\text { reumatoide (4) }\end{array}$ \\
\hline Anticoagulante lúpico $\mathrm{n}(\%)$ & $7(54 \%)$ & $3(75 \%)$ \\
\hline Anticardiolipina lgG $\mathrm{n}(\%)$ & $3(23 \%)$ & $1(25 \%)$ \\
\hline Ambos $\mathrm{n}(\%)$ & $3(23 \%)$ & $0(0 \%)$ \\
\hline
\end{tabular}

Al analizar los resultados según el sexo, del $17 \%$ de prevalencia solo un paciente fue varón (1\%).

En el grupo control, solo se encontró una mujer con anticoagulante lúpico positivo, correspondiéndole $2 \%$ dentro de su grupo (tabla 2).

No se halló alteraciones en el perfil de coagulación de los grupos de estudio.

\section{DISCUSIÓN}

Actualmente, la población mundial tiene una mayor expectativa de vida debido a los avances en la medicina y en la salud pública. Si bien el Perú está comprendido entre el grupo de países en desarrollo, su población en la actualidad tiene mayor expectativa de vida, sobretodo en la costa ${ }^{(10)}$.

Es conocido que a medida que la población envejece es más susceptible a presentar enfermedades neoplásicas y autoinmunes, como son las conectivopatías ${ }^{(11)}$.

Las conectivopatías presentan diferentes alteraciones hematológicas; una de ellas es la presencia de trombosis, ya sea venosa y/o arterial. Estudios realizados en los países desarrollados relacionan la presentación de trombosis con el hallazgo de anticuerpos antifosfolípidos en pacientes con conectivopatías, sobre todo con anticoagulante lúpico y anticardiolipina $\operatorname{IgG}{ }^{(12-14)}$.

En el presente estudio, el hallazgo de $17 \%$ de anticuerpos antifosfolipídicos demuestra que estos son frecuentes en estas enfermedades, tal y como lo refiere la literatura ${ }^{(15)}$. Este dato debe ser tenido en cuenta para evitar que estas personas presenten un cuadro de trombosis clínica durante su evolución; por lo tanto, deben estar bajo control médico.

Otro dato resaltante es que la mayoría de pacientes con conectivopatías y anticuerpos antifosfolípidos positivos fueron de sexo femenino ${ }^{(16)}$. Esto se puede deber a que el lupus eritematoso sistémico es más frecuente en mujeres $^{(17)}$.

En relación al grupo control, solo se encontró una mujer con anticoagulante lúpico positivo, confirmando la prevalencia baja de los anticuerpos antifosfolípidos en personas sanas ${ }^{(18)}$. El anticoagulante lúpico fue el anticuerpo más frecuente, $10 \%$ del total. Es conocida su relación con cuadros de trombosis, especialmente en el lecho venoso ${ }^{(19)}$. La decisión de dar tratamiento para prevenir este cuadro clínico debe ser tomada analizando la presencia de otros factores de riesgo, tales como dislipidemias, diabetes, hipertensión arte-

Tabla 2. Distribución de la población por positividad o negatividad a anticuerpos antifisfolípidos.

\begin{tabular}{|c|c|c|}
\hline Anticuerpos antifosfolípidos & $\begin{array}{c}\text { Paciente con conectivopatía } \\
n(\%)\end{array}$ & $\begin{array}{c}\text { Paciente sano } \\
n(\%)\end{array}$ \\
\hline Sí (18) & $17(94 \%)$ & $1(6 \%)$ \\
\hline No (132) & $83(63 \%)$ & $49(37 \%)$ \\
\hline
\end{tabular}

rial, limitación funcional. En todo caso, la responsabilidad debe ser compartida entre el reumatólogo y el hematólogo.

Algunos estudios anteriores realizados en diferentes poblaciones con enfermedades del tejido conectivo, como el lupus eritematoso sistémico, han estimado que la prevalencia de los anticuerpos antifosfolipídicos es aproximadamente $10 \%$ a $80 \%{ }^{(20-23)}$.

En un estudio (20), la prevalencia global de anticuerpos antifosfolipídicos fue $53,7 \%$, la de anticoagulante lúpico $34,1 \%$, anticardiolipina IgM 31,8\%, anticardiolipina IgG 18,2\%, anti-beta2glicoproteína IgM 5,7\% y anti-beta2glicoproteína IgG 5,7\%. Las frecuencias de porcentajes de anticuerpos antifosfolipídicos fueron similares a las descritos en los estudios anteriores, excepto por el de anti-beta2-glicoproteína; la prevalencia de antibeta2-glicoproteína en el presente estudio fue menor que lo informado en estudios realizados en países occidentales ${ }^{(22-24)}$.

A partir de nuestros hallazgos, concluimos que la prevalencia de anticuerpos antifosfolípidos en pacientes con conectivopatías de nuestra población fue $17 \%$. La conectivopatía estudiada más frecuente fue el lupus eritematoso sistémico ${ }^{(25)}$. El anticuerpo antifosfolípido más frecuente fue el anticoagulante lúpico, presentándose en 10\% del total de pacientes con conectivopatías.

\section{REFERENCIAS BIBLIOGRÁFICAS}

1. Woo KS, Kim KE, Kim JM, Han JY, Chung WT, $\mathrm{Kim} \mathrm{KH}$. Prevalence and clinical associations of lupus anticoagulant, anticardiolipin antibodies, and anti-beta2-glycoprotein I antibodies in patients with systemic lupus erythematosus. Korean J Lab Med. 2010;30(1):38-44.

2. Sans Sabrafen. Hematologia Clínica. ( $4^{\circ}$ ed). Madrid: Ediciones Harcourt SA. 2007.

3. Folsom AR. Hemostatic risk factors for atherothrombotic disease: An epidemiologic review. Thrombosis Hemostasis. 2001;86:366.

4. George J, Shoenfeld Y. The antiphospholipid (Hughes) syndrome: a crossroads of autoimmunity and atherosclerosis. Lupus. 1997;6:559-60.

5. Galli M, Luciani D, Bertolini G, Barbui T. Lupus anticoagulants are stronger risk factors for thrombosis than anticardiolipin antibodies in the antiphospholipid syndrome: a systematic review of the literature. Blood. 2003;101:1827-32. 
6. Galli M, Barbui T. Antiphospholipid antibodies and pregnancy. Best Pract Res Clin Haematol. 2003;16:211-25

7. Somers E, Magder LS, Petri M. Antiphospholipid antibodies and incidence of venous thrombosis in a cohort of patients with systemic lupus erythematosus. J Rheumatol. 2002;29:2531-6.

8. Ruiz-Irastorza G, Crowther M, Branch W, Khamashta MA. Antiphospholipid syndrome. Lancet. 2010;376(9751):1498-509.

9. Disponible en el Portal web del Ministerio de Salud del Perú: http://www.minsa.gob.pe/estadisticas/ estadisticas/indicadoresSalud/morbilidad/sida/ SidaMacros.asp?00.

10. Disponible en el Portal web Ministerio de Salud de Perú: http://www.minsa.gob.pe/estadisticas/estadisticas/indicadoresSalud/demograficos/esperanza/ ESPVIDMacros.asp?00.

11. Chakravarty E, Genovese MC. Rheumatic syndromes associated with malignancy. Curr Opin Rheumatol. 2003;15:35-43.

12. Triplett DA, Brandt JT. Lupus anticoagulants: misnomer, paradox, riddle, epiphenomenon. Hematol Pathol. 1995;2:121-43.

13. Favaloro EJ, Wong RC, Silvestrini R, McEvoy R, Jovanovich S, Roberts-Thomson P. A multilaboratory peer assessment quality assurance program-based evaluation of anticardiolipin antibody, and beta2glycoprotein I antibody testing. Semin Thromb Hemost. 2005;31(1):73-84.

14. Cervera R, Piette JC, Font J, Khamashta MA, Shoenfeld Y, et al. Antiphospholipid syndrome: clinical and immunologic manifestations and patterns of disease expression in a cohort of 1,000 patients. Arthritis Rheum. 2002;46(4):1019-27.

15. Tripodi A. Testing for lupus anticoagulants: all that a clinician should know. Lupus. 2009;18(4):291-8.

16. Staudinger T, Locker GJ, Frass M. Management of acquired coagulation disorders in emergency and intensive-care medicine. Semin Thromb Hemost. 1996;22(1):93-104.

17. Mc Neil HP, Chesterman CN, Krilis SA. Immunology and clinical importance of antiphospholipid antibodies. Adv Immunol. 1991;49:193.280.

18. Roubey RA, Pratt CW, Buyon JP, Winfield JB. Lupus anticoagulant activity of autoimmune antiphospholipid antibodies is dependent upon B2-glycoprotein I. J Clin Invest. 1992;90(3):1100-4.

19. Harris EN, Boey ML, Mackworth-Young CG, Gharavi AE, Patel BM, Loizou S, Hughes GRV. Antocardiolipin antibodies: detection by radioimmunoassay and association with thrombosis in systemic lupus erythematosus. Lancet. 1983;322 (8361):1211-4.

20. Ghirardello A, Doria A, Ruffatti A, Rigoli AM, Vesco $P$, Calligaro A, et al. Antiphospholipid antibodies $(\mathrm{aPL})$ in systemic lupus erythematosus. Are they specific tools for the diagnosis of aPL syndrome? Ann Rheum Dis. 1994;53:140-2.

21. Petri M. Epidemiology of the antiphospholipid antibody syndrome. J Autoimmun. 2000;15:145-51.

22. Danowski A, Kickler TS, Petri M. Anti-beta2glycoprotein I: prevalence, clinical correlations, and importance of persistent positivity in patients with antiphospholipid syndrome and systemic lupus erythematosus. J Rheumatol. 2006;33:1775-9.
23. Mok MY, Chan EY, Fong DY, Leung KF, Wong WS, Lau CS. Antiphospholipid antibody profiles and their clinical associations in Chinese patients with systemic lupus erythematosus. J Rheumatol. 2005;32:622-8.

24. Lee SG, Cha HS, Yang YS. The association of HLA-DRB1 and DQB1 alleles and a study of anticardiolipin antibody and anti-beta2 glycoprotein I antibody in Korean SLE patients. Immune Netw. 2002;2:227-32.

25. Swadzba J, Iwaniec T, Szczeklik A, Musial J. Revised classification criteria for antiphospholipid syndrome and the thrombotic risk in patients with autoimmune diseases. J Thromb Haemost. 2007:5:1883-9.

Trabajo presentado a las IX Jornadas Cientificas Sanfernandinas, XII Jornadas de Investigación en Salud, XIX Jornadas Sanfernandinas Estudiantiles, Facultad de Medicina, UNMSM, setiembre 2010.

\section{Correspondencia:}

Dr. Oscar Ruiz Franco

Instituto de Investigaciones Clínicas, Facultad de Medicina, UNMSM

Hospital Nacional 2 de Mayo Lima 1, Perú

Parque Historia de la Medicina Peruana s/n

Correo electrónico: osmaruf@gmail.com 